\title{
Adherence to statin treatment following a myocardial infarction: an Italian population-based survey
}

This article was published in the following Dove Press journal:

ClinicoEconomics and Outcomes Research

I June 2015

Number of times this article has been viewed

\section{Bruno Monaldi ${ }^{1}$ \\ Giovanni Bologna2 \\ Geeta Giulia Costa ${ }^{3}$ \\ Carlo D'Agostino ${ }^{4}$ \\ Fulvio Ferrante ${ }^{5}$ \\ Maurizio Filice ${ }^{6}$ \\ Anna Maria Grion ${ }^{7}$ \\ Alessandra Mingarelli ${ }^{8}$ \\ Leonardo Paloscia ${ }^{9}$ \\ Roberto Tettamanti ${ }^{10}$ \\ Chiara Veronesi"l \\ Luca Degli Esposti"l}

'Servizio Farmaceutico, Ospedale G Mazzoni, ASUR Marche, Ascoli Piceno,

2Dipartimento Farmaceutico, Ospedale

di Piacenza, AUSL di Piacenza, SSR

Emilia-Romagna, Piacenza, ${ }^{3}$ Dipartimento

Scienze Cardiologiche, Toraciche e

Vascolari, Università degli Studi di Padova,

Padua, ${ }^{4}$ Unità Operativa Cardiologia,

Ospedale Di Venere, ASL di Bari, Bari,

${ }^{5} \mathrm{SC}$ Monitoraggio Attività Farmaceutica,

Azienda USL Frosinone, Frosinone,

${ }^{6}$ Dipartimento Medico, Ospedale Piero

Palagi, Azienda Sanitaria di Firenze (ASF),

Florence, ${ }^{7}$ Servizio Farmaceutico, ULSS 16

Padova, Padua, ${ }^{8}$ Dipartimento Funzionale

del Farmaco, ASL di Latina, Latina,

'Unità Operativa UTIC e Cardiologia

Interventistica, Ospedale Santo Spirito,

ASL di Pescara, Pescara, ${ }^{10}$ Unità Operativa

Complessa Osservatorio Epidemiologico e

Sistemi Informativi, ASL della Provincia di

Como, Como, "CliCon Health, Economics

and Outcomes Research, Ravenna, Italy

Correspondence: Luca Degli Esposti CliCon Health, Economics and Outcomes Research, 36 Via Salara, Ravenna 48I00, Italy

Tel +39054438393

Fax +390544 212 699

Email luca.degliesposti@clicon.it
Background: Statins are standard therapies after myocardial infarction (MI) in the general population. In the current study, we assessed adherence to statin treatment by patients after an MI in Italy, and estimated the effect of in-hospital statin therapy on persistence in treatment during a 2-year follow-up.

Patients and methods: This was a retrospective cohort observation study of patients who experienced their MI between January 1, 2004 and December 31, 2005. Patients to enroll were identified by a diagnosis of MI at discharge from hospital. Previous drug therapies and hospital admissions for cardiovascular reasons in the 12 months before hospitalization for MI, statin treatment and lipid levels during hospitalization, indication for statin treatment at hospital discharge, and adherence to statin treatment in the following 24 months using an integrated analysis of administrative databases and hospital case records were evaluated. Also, factors associated either positively or negatively with consistent acute and long-term use of this efficacy-proven therapy were evaluated.

Results: We identified 3,369 patients: $28.5 \%$ of patients had not been consistently treated with statins during their hospital stay for MI, and $36.2 \%$ of patients did not receive a statin prescription at hospital discharge. Of the 2,629 patients persistent with treatment during the follow-up, only 1,431 had an adherence to statins $>80 \%$. Either during the hospitalization or during the follow-up, the use of statins was negatively associated with older age and the presence of diabetes and chronic kidney disease. Lipid levels were significantly higher in treated than in untreated patients, but did not contribute to adherence to treatment. An important factor in long-term adherence to statin treatment was a statin prescription at the time of hospital discharge.

Conclusion: Since the statin undertreatment rate in routine care is still high, physicians need to increase the awareness of patients regarding the implications of discontinuation and/or underuse of their medications and encourage higher adherence.

Keywords: myocardial infarction, statins, adherence to treatment, discontinuation

\section{Introduction}

There is general agreement that all coronary artery disease (CAD) patients should be treated with statins irrespective of their serum cholesterol level. ${ }^{1-4}$ Moreover, in patients with acute coronary syndrome, early statin therapy using high-dose atorvastatin significantly lowered recurrent ischemic events. ${ }^{5}$ Despite the well-established benefits and abundance of clinical management guidelines advocating statin use in high-risk cardiac conditions, ${ }^{6-8}$ the direct translation of trial results to individual patients in clinical practice is however still unsatisfactory. The therapeutic effect of a drug depends not only on patients having the treatment prescribed but also on their adherence with the treatment. Data from the US show that only half to three-quarters 
of patients who have had a myocardial infarction (MI) are even being screened for serum cholesterol levels, much less being prescribed lipid-lowering regimens. ${ }^{9}$ Moreover, previous studies have shown that long-term adherence to statin regimens in patients who are appropriate candidates has generally been poor, and continued use of statins drops substantially over time. ${ }^{10,11}$ In this context, the environment in which healing and disease prevention take place, including the behavior of physician and that of patients, play a leading role. Programs aimed at fostering systems-based hospital care of CAD patients from admission to discharge incorporating evidence-based tools into practice and targeting patients resulted in a significant lowering of short- and long-term mortality. ${ }^{12}$ This is important, since it is known that prescription for statins at the time of hospital discharge enhances long-term statin adherence. ${ }^{13}$

The present study aimed to investigate adherence to statin treatment by patients after an MI in Italy, and to estimate the effect of in-hospital statin therapy on persistence in treatment during a 2-year follow-up.

\section{Patients and methods \\ Data source}

In a nonconcurrent cohort study design, data were abstracted from administrative databases maintained by nine local health units (LHUs) in Italian regions in the north (Lombardy, Veneto, Emilia-Romagna), the center (Tuscany, Abruzzo, Lazio), and the south (Apulia). Overall, the served populations include approximately 4,000,000 inhabitants. Each LHU ethics committee approved the study. The databases used were beneficiaries, pharmacy claims, hospital discharges, and mortalities, and were all linked using the fiscal code as a unique identifier. Beneficiary and pharmacy claim databases are updated monthly, the hospital discharge database every 2 or 3 months, and the mortality database annually. Universal health care coverage in Italy allows completeness and comprehensiveness of the information contained in these databases, which in a previous epidemiological study showed almost complete $(>95 \%)$ linkage. ${ }^{14}$ The Italian Ministry of Health has reported that archives are $100 \%$ complete and $95 \%$ accurate..$^{15}$ In order to guarantee patient privacy, each subject was assigned an anonymous univocal alphanumeric code.

\section{Cohort definition}

Records of patients aged 18 years or over discharged from hospital between January 1, 2004 and December 31, 2005 with a main diagnosis of MI (International Classification of Diseases [ICD]-9 code 410), were selected from the hospital discharge database, which contains the dates of hospital admission and discharge and the discharge diagnoses. We excluded subjects who died, as well as those who moved to other LHUs in a 24-month follow-up, starting from the date of hospital discharge (index date). The same database provided information also on occurrence of hospital admissions in the 12 months preceding the index date for the following reasons: coronary heart disease (ICD-9 410-414), heart failure (ICD-9 428), cerebrovascular disease (ICD-9 430-438), peripheral vascular disease (ICD-9 440-443), and diabetes (ICD-9 250). From the beneficiary database, demographics, place of residence, and date of entry in and exit from the database were obtained. The pharmacy claim database is generated from requests to the LHUs for reimbursement of prescription drugs dispensed by pharmacies to outpatients in the community and covered by the Italian National Health Service. It was used to retrieve the prescribing physician's code, the anatomical-therapeuticchemical (ATC) code, the number of packs, the number of units per pack, the dosage (strength per unit drug), the cost per pack, and the prescription date of each drug dispensed. The defined daily dose of statin has been established by the World Health Organization: ${ }^{16} 20 \mathrm{mg}$ for atorvastatin, $30 \mathrm{mg}$ for pravastatin, $10 \mathrm{mg}$ for rosuvastatin, and $30 \mathrm{mg}$ for simvastatin. The presence of at least two prescriptions for hypoglycemic drugs (ATC code A10), antiplatelet drugs (ATC code B01), and antihypertensive drugs (ATC codes C02, C03, C07, C08, and C09) was considered to represent a treatment for diabetes, prevention of thrombosis, and hypertension, respectively, either in the 12-month period prior or in the 24-month period following the index date. In-hospital case history had been looked up to check determination of total and low-density-lipid (LDL) cholesterol levels (in cases of two or more values, we had considered the first determination), in-hospital statin treatment, and statin prescription at discharge from the hospital. The mortality database was used to obtain vital status and date of death in the follow-up.

\section{Adherence to statin treatment}

The adherence to statin treatment was determined in the 24-month follow-up period. Patients who received only one prescription for statin were defined as “occasionals". In persistent patients (those who received two or more prescriptions), adherence was determined using the medication-possession 
ratio (MPR). The MPR reflects the proportion of days during which the patients possessed a supply medication:

$$
\text { MPR }=\frac{\text { Sum of days' supply during follow-up period }}{\text { Total number of days of follow-up period (730) }}
$$

For patients treated with two or more statins, the MPR reported was calculated as the mean of the MPR calculated for each drug. We excluded from the MPR calculation the number of days eventually spent by the patient in an institutionalized care setting, such as a hospital. Patients were defined as adherent to statin treatment if their MPR was equal or over $80 \% .{ }^{17}$ The mean daily dose of statin, expressed in $\mathrm{mg} /$ day, was calculated as the total amount of statin/the number of days of follow-up.

\section{Statistical analysis}

Data are summarized as means \pm standard deviation for continuous variables and as percentages for categorical variables. Differences in categorical variables were tested using Pearson's $\chi^{2}$ test, considering results for trend when appropriate.

Logistic regression, with relative risk and 95\% confidence interval, was used to predict 2-year nonadherence to statin treatment. Covariates included in the models were demographics (age and sex), statin treatment before hospital admission, diabetes, previous cardiovascular (CV) hospitalizations, chronic kidney disease (CKD), statin treatment during hospitalization, concomitant antihypertensive and antithrombotic treatments, and statin prescribed during the follow-up. Analyses were performed using the SPSS statistical package, version 20.0 for Windows (IBM, Armonk, NY, USA). A $P$-value $<0.05$ was considered statistically significant.

\section{Results}

Over the 2-year period, 3,848 subjects were discharged from hospital with a main diagnosis of MI. Of these, 3,369 (1,036 women, mean age 69.0 \pm 11.9 years, and 2,333 men, mean age $60.6 \pm 12.6$ years) satisfied the inclusion/exclusion criteria. The age distribution for women of 76 (7.3\%), 402 (38.8\%), and $558(53.9 \%)$ aged $<50,50-69$, and $70+$ years, respectively, and for men, 465 (19.9\%), 1,268 (54.4\%), and $600(25.7 \%)$ aged $<50,50-69$, and 70+ years, respectively, was significantly different $(P<0.001)$. Prevalence of previous $\mathrm{CV}$ hospitalization, diabetes, and CKD was $37.9 \%, 26.2 \%$, and $7.8 \%$, respectively, while $1,689(50.1 \%)$ patients had been treated with statins and/or antihypertensive drugs and/or antiplatelet drugs in the 12 months before hospital admission. Statins had been prescribed to 570 (16.9\%) patients. During hospitalization, 2,409 (71.5\%) patients had been treated by statins (Table 1). Treated patients compared to untreated patients were more frequently male, older, and had a higher prevalence of previous CV hospital admissions and a lower prevalence of concomitant diseases. At least a measurement of total cholesterol and LDL cholesterol was present in 3,006 $(89.2 \%)$ and in $2,558(75.9 \%)$ of patients, respectively. The mean value of both parameters and the percentage of value over the recommended target were significantly higher in treated than in untreated patients (Table 1). At discharge from the hospital, statin treatment had been prescribed to 2,150 $(63.8 \%)$ patients, and had not been prescribed to $833(24.7 \%)$ patients. In $386(11.5 \%)$ patients, we found no indication regarding statin treatment in the hospital patient case history (Table 2). Younger age, male sex, in-hospital statin treatment, and total and LDL cholesterol levels were significantly different in the three cohorts of patients. The statin prescribed at hospital discharge was generally confirmed by the first prescription made out of hospital, with a percentage ranging from $75 \%$ for rosuvastatin up to $87 \%$ for simvastatin (Table 3 ). Among the patients without a prescription of statin at hospital discharge, $412(49.5 \%)$ received a prescription of statin out of the hospital. Among the patients with unknown

Table I Participant characteristics by statin treatment during hospitalization

\begin{tabular}{|c|c|c|c|}
\hline & \multicolumn{2}{|c|}{$\begin{array}{l}\text { Statin treatment } \\
\text { during hospitalization, } \\
\text { n (\%)/mean } \pm \text { SD }\end{array}$} & \multirow[t]{3}{*}{$\mathbf{P}<$} \\
\hline & No & Yes & \\
\hline & $960(28.5)$ & 2,409 (7I.5) & \\
\hline Age, years & $67.3 \pm 13.1$ & $61.6 \pm 12.6$ & 0.001 \\
\hline Sex, male & $600(62.5)$ & I,733 (7I.9) & 0.001 \\
\hline $\begin{array}{l}\text { Hospitalization for } \mathrm{CV} \text { reasons } \\
\text { in the previous year }\end{array}$ & $352(36.7)$ & $926(38.4)$ & NS \\
\hline Presence of diabetes $\mathrm{s}^{\mathrm{a}, \mathrm{b}}$ & $290(30.2)$ & $594(24.7)$ & 0.001 \\
\hline Presence of $C K D^{a}$ & $110(11.5)$ & $154(6.4)$ & 0.001 \\
\hline Total cholesterol, ${ }^{\mathrm{c}, \mathrm{d}} \mathrm{mg} / \mathrm{dL}$ & $174.8 \pm 50.5$ & $194.3 \pm 55.4$ & 0.001 \\
\hline LDL-C, ,ee mg/dL & $107.4 \pm 40.6$ & $124.3 \pm 45.7$ & 0.001 \\
\hline $\mathrm{LDL}-\mathrm{C}>100 \mathrm{mg} / \mathrm{dL}$ & $396(58.1)$ & I,395 (74.4) & 0.001 \\
\hline $\mathrm{LDL}-\mathrm{C}>70 \mathrm{mg} / \mathrm{dL}$ & $590(86.6)$ & I,698 (90.5) & 0.01 \\
\hline
\end{tabular}

Notes: ${ }^{2}$ As inferred from hospital discharge database; ${ }^{b}$ as inferred from preadmission prescription of specific drugs; ' as inferred from hospital case history; ${ }^{d a s}$ inferred from 3,006 of 3,369 (89.2\%) hospital case histories; eas inferred from 2,558 of 3,369 (75.9\%) hospital case histories.

Abbreviations: SD, standard deviation; CV, cardiovascular; NS, not significant; CKD, chronic kidney disease; LDL-C, low-density-lipoprotein cholesterol. 
Table 2 Participant characteristics by statin prescription at discharge

\begin{tabular}{|c|c|c|c|c|}
\hline & \multicolumn{3}{|c|}{$\begin{array}{l}\text { Statin prescription at hospital } \\
\text { discharge }^{a} \text {, n (\%)/mean } \pm \text { SD }\end{array}$} & \multirow[t]{2}{*}{$\mathbf{P}<$} \\
\hline & $\begin{array}{l}\text { Yes } \\
2,150(63.8)\end{array}$ & $\begin{array}{l}\text { No } \\
833(24.7)\end{array}$ & $\begin{array}{l}\text { Unknown } \\
386(11.5)\end{array}$ & \\
\hline Age, years & $61.2 \pm 12.5$ & $67.3 \pm 13.0$ & $65.7 \pm 12.6$ & 0.001 \\
\hline Sex, male & I,54| (7I.7) & $510(61.2)$ & $282(73.1)$ & 0.001 \\
\hline $\begin{array}{l}\text { Statin treatment } \\
\text { during hospitalization }\end{array}$ & $2,076(96.6)$ & $107(12.8)$ & $226(58.5)$ & 0.001 \\
\hline $\begin{array}{l}\text { Total cholesterol, } \\
\mathrm{mg} / \mathrm{dL}\end{array}$ & $193.1 \pm 57.5$ & $175.2 \pm 50.0$ & $194.1 \pm 49.6$ & 0.001 \\
\hline LDL-C, ${ }^{c} \mathrm{mg} / \mathrm{dL}$ & $123.9 \pm 45.6$ & $108.5 \pm 40.5$ & $117.0 \pm 46.7$ & 0.001 \\
\hline LDL-C $>100 \mathrm{mg} / \mathrm{dL}$ & I,307 (74.I) & $36 I$ (59.9) & $125(65.1)$ & 0.001 \\
\hline LDL-C $>70$ mg/dL & I,596 (90.5) & $522(86.7)$ & $169(88.0)$ & 0.05 \\
\hline
\end{tabular}

Notes: ${ }^{a}$ As inferred from hospital case history; bas inferred from 3,006 of 3,369 (89.2\%) hospital case histories; 'as inferred from 2,558 of 3,369 (75.9\%) hospital case histories.

Abbreviations: SD, standard deviation; LDL-C, low-density-lipoprotein cholesterol.

indications for statins at hospital discharge, 293 (75.9\%) patients received a prescription of statin out of the hospital. The statin more frequently prescribed was atorvastatin $(1,132$ patients), followed by simvastatin (1,127 patients), pravastatin (305 patients), rosuvastatin (130 patients), and other statins (50 patients). A weak difference in mean total cholesterol levels was present among the different types of statins prescribed (atorvastatin was more frequently prescribed for patients with higher values), while no relationship was found between LDL cholesterol levels and types of statins prescribed (Table 4).

For outpatients, 2,744 (81.4\%) patients received at least one prescription of statin, while $625(18.6 \%)$ did not receive prescriptions of statins during the 24-month follow-up period. Younger age, male sex, in-hospital statin treatment, statin prescriptions at hospital discharge, and total and LDL cholesterol levels were significantly more frequent or higher in treated than in untreated patients, while previous hospital admission for $\mathrm{CV}$ disease and presence of concomitant diseases were more frequent in untreated than treated patients (Table 5). Among the 2,744 patients treated with statins as outpatients, 115 (4.2\%) were defined as occasionals, since they received only one prescription of statin. Occasional patients compared to those persistent were older, more frequently female with concomitant diseases, with a lower percentage of statin treatment during the hospital stay, and lower percentage of statin prescription at discharge from the hospital (Table 6). Among persistent patients, 1,999 (76\%) were treated by the same type of statin, $543(20.7 \%)$ by two different type of statins, and $87(3.3 \%)$ by three or more types of statins. Among persistent patients, 1,431 (54.4\%) patients showed an MPR $\geq 80 \%$ (Table 7). Percentage of statin treatment during hospitalization and statin prescription at hospital discharge, mean age, and prevalence of male sex were significantly different between the two cohorts of patients. In persistent patients with an adherence to treatment $\geq 80 \%$, we calculated the daily dose of different types of statins during the 2-year follow-up (Table 8). For atorvastatin, there was an equivalent number of patients treated by a dose $\leq 20 \mathrm{mg}$ or a dose ranging from $20 \mathrm{mg}$ to $40 \mathrm{mg}$ ( $44.2 \%$ and $47.7 \%$, respectively). For pravastatin, the majority of patients $(71.3 \%)$ were treated by a dose ranging from $30 \mathrm{mg}$ to $60 \mathrm{mg}$. For rosuvastatin, there was a weak prevalence of patients treated by a dose $\leq 10 \mathrm{mg}$ rather than a dose ranging from $10 \mathrm{mg}$ to $20 \mathrm{mg}(53.7 \%$ and $42.6 \%$, respectively). For simvastatin, there was a weak

Table 3 Relationship between statin prescription at hospital discharge and first statin prescription out of the hospital

\begin{tabular}{|c|c|c|c|c|c|c|c|}
\hline \multirow{2}{*}{$\begin{array}{l}\text { Statin prescribed at } \\
\text { hospital discharge, n \% }\end{array}$} & \multicolumn{6}{|c|}{ First statin prescribed at the beginning of follow-up, $n \%$} & \multirow[t]{2}{*}{ Total } \\
\hline & Atorvastatin & Pravastatin & Rosuvastatin & Simvastatin & Other statins ${ }^{a}$ & No statins & \\
\hline \multirow[t]{2}{*}{ Atorvastatin } & 786 & 13 & 20 & 63 & 5 & 52 & 939 \\
\hline & 83.7 & 1.4 & 2.1 & 6.7 & 0.5 & 5.5 & 100 \\
\hline \multirow[t]{2}{*}{ Pravastatin } & 24 & 196 & 5 & 14 & I & 15 & 255 \\
\hline & 9.4 & 76.9 & 2.0 & 5.5 & 0.4 & 5.9 & 100 \\
\hline \multirow[t]{2}{*}{ Rosuvastatin } & 3 & I & 33 & 6 & 0 & 1 & 44 \\
\hline & 6.8 & 2.3 & 75.0 & 13.6 & & 2.3 & 100 \\
\hline \multirow[t]{2}{*}{ Simvastatin } & 39 & 22 & 10 & 786 & 3 & 43 & 903 \\
\hline & 4.3 & 2.4 & I.I & 87.0 & 0.3 & 4.8 & 100 \\
\hline \multirow[t]{2}{*}{ Other statins } & 2 & 0 & 0 & 0 & 7 & 0 & 9 \\
\hline & 22.2 & & & & 77.8 & & 100 \\
\hline \multirow[t]{2}{*}{ No statins } & 155 & 42 & 50 & $|4|$ & 24 & 421 & 833 \\
\hline & 18.6 & 5.0 & 6.0 & 16.9 & 2.9 & 50.5 & 100 \\
\hline \multirow[t]{2}{*}{ Unknown } & 123 & 31 & 12 & 117 & 10 & 93 & 386 \\
\hline & 31.9 & 8.0 & 3.1 & 30.3 & 2.6 & 24.1 & 100 \\
\hline Total, $\mathrm{n}$ & 1,132 & 305 & 130 & I,I27 & 50 & 625 & 3,369 \\
\hline
\end{tabular}

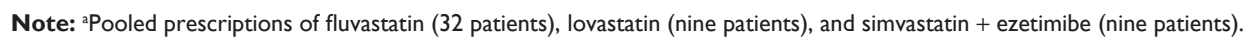


Table 4 Relationship between cholesterol levels and first statin prescription out of the hospital

\begin{tabular}{|c|c|c|c|c|c|c|}
\hline & \multicolumn{5}{|c|}{ Statin treatment in follow-up, $n(\%) /$ mean \pm SD } & \multirow[t]{2}{*}{$\mathbf{P}<$} \\
\hline & $\begin{array}{l}\text { Atorvastatin } \\
I, 132(4 \mid .3)\end{array}$ & $\begin{array}{l}\text { Pravastatin } \\
305 \text { (I I.I) }\end{array}$ & $\begin{array}{l}\text { Rosuvastatin } \\
\text { I } 30(4.7)\end{array}$ & $\begin{array}{l}\text { Simvastatin } \\
\text { I, I } 27 \text { (4I.I) }\end{array}$ & $\begin{array}{l}\text { Other statins } \\
50(1.8)\end{array}$ & \\
\hline Total cholesterol, ${ }^{\mathrm{a}} \mathrm{mg} / \mathrm{dL}$ & $196.5 \pm 54.1$ & $190.6 \pm 55.5$ & $191.3 \pm 62.3$ & $189.1 \pm 58.4$ & $198.4 \pm 57.8$ & 0.05 \\
\hline $\mathrm{LDL}-\mathrm{C}, \mathrm{b} \mathrm{mg} / \mathrm{dL}$ & $125.4 \pm 45.0$ & $|22.8 \pm 47|$. & $120.0 \pm 46.6$ & $120.6 \pm 46.2$ & $129.6 \pm 51.6$ & NS \\
\hline $\mathrm{LDL}-\mathrm{C} \geq 100 \mathrm{mg} / \mathrm{dL}$ & $682(72.5 \%)$ & $202(78.3 \%)$ & 77 (76.2\%) & $597(73.1 \%)$ & $28(71.8 \%)$ & NS \\
\hline LDL-C $\geq 70 \mathrm{mg} / \mathrm{dL}$ & $854(90.8 \%)$ & 237 (91.9\%) & $90(89.1 \%)$ & $730(89.4 \%)$ & $36(92.3 \%)$ & NS \\
\hline
\end{tabular}

Notes: a As inferred from 2,479 of 2,744 (90.3\%) hospital case histories; bas inferred from 2,156 of 2,744 (78.6\%) hospital case histories.

Abbreviations: SD, standard deviation; LDL-C, low-density-lipoprotein cholesterol; NS, not significant.

prevalence of patients treated by a dose ranging from $30 \mathrm{mg}$ to $60 \mathrm{mg}$ rather than a dose $\leq 30 \mathrm{mg}(53.3 \%$ and $45.7 \%$, respectively).

Logistic regression analysis with relative risk and 95\% confidence interval was used to predict 2-year nonadherence to statin treatment (Table 9). Neither sex nor CKD had a significant role in determining adherence to statin treatment. A significant decrease in adherence was related to increasing age and presence of previous CV diseases, as well as diabetes. A significant increase in adherence was related to statin treatment before actual MI, statin treatment during hospitalization for actual MI, and contemporary treatment with antihypertensive and antiplatelet drugs during the 2-year follow-up. With regard to the type of statin, atorvastatin, which was selected as the reference as the most frequently prescribed, resulted in the best treatment adherence.

Table 5 Participant characteristics by statin treatment at follow-up

\begin{tabular}{|c|c|c|c|}
\hline & \multicolumn{2}{|c|}{$\begin{array}{l}\text { Statin treatment } \\
\text { at follow-up, } \\
\text { n (\%)/mean } \pm \text { SD }\end{array}$} & \multirow[t]{3}{*}{$\mathbf{P}<$} \\
\hline & & Yes & \\
\hline & $625(18.6)$ & $2,744(81.4)$ & \\
\hline Age, years & $70.7 \pm 13.2$ & $61.5 \pm 12.8$ & 0.001 \\
\hline Sex, male & $352(56.3)$ & I,98I (72.2) & 0.001 \\
\hline $\begin{array}{l}\text { Hospitalization for } \mathrm{CV} \text { reasons } \\
\text { in the previous year }{ }^{\mathrm{a}}\end{array}$ & $26 I(4 I .8)$ & $\mathrm{I}, 017(37.1)$ & 0.05 \\
\hline Presence of diabetes ${ }^{\mathrm{a}, \mathrm{b}}$ & 191 (30.6) & $693(25.3)$ & 0.01 \\
\hline Presence of $C K D^{a}$ & $84(13.6)$ & $180(6.6)$ & 0.001 \\
\hline $\begin{array}{l}\text { Statin treatment during } \\
\text { hospitalization }^{c}\end{array}$ & 177 (28.3) & $2,232(81.3)$ & 0.001 \\
\hline Prescription of statins at discharge ${ }^{d}$ & I I I (20.9) & $2,039(83.2)$ & 0.001 \\
\hline Total cholesterol,e mg/dL & $172.2 \pm 46.2$ & $192.7 \pm 56.5$ & 0.001 \\
\hline LDL-C, ${ }^{f} \mathrm{mg} / \mathrm{dL}$ & $103.8 \pm 36.8$ & $122.8 \pm 45.7$ & 0.001 \\
\hline LDL-C > $>00 \mathrm{mg} / \mathrm{dL}$ & $206(51.5)$ & $\mathrm{I}, 588(73.6)$ & 0.001 \\
\hline LDL-C >70 mg/dL & $339(84.8)$ & $1,949(90.3)$ & 0.001 \\
\hline 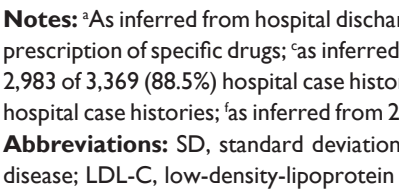 & $\begin{array}{l}558 \text { of } 3,369 \text { (75 } \\
\mathrm{CV} \text {, cardiovasc } \\
\text { cholesterol. }\end{array}$ & $\begin{array}{l}\text { nferred from prea } \\
\text { e history; das infer } \\
\text { rom } 3,006 \text { of } 3,36 \\
9 \%) \text { hospital case } \\
\text { ular; CKD, chron }\end{array}$ & $\begin{array}{l}\text { Imission } \\
\text { ed from } \\
(89.2 \%) \\
\text { istories. } \\
\text { kidney }\end{array}$ \\
\hline
\end{tabular}

\section{Discussion}

In this study of in-hospital and 2-year adherence to the use of statin for secondary prevention following an MI, we found that patient use of evidence-based therapy remains suboptimal. More concerning, $28.5 \%$ of patients had not been consistently treated with statins during their hospital stay for MI, and $36.2 \%$ of patients did not received a statin prescription at hospital discharge. Moreover, for outpatients, 57.6\% of patients were not treated, occasional users, or underusers (MPR lower than 80\%). A number of measured factors were associated either positively or negatively with consistent acute and long-term use of this efficacy-proved therapy. In the present study, statins were less frequently prescribed to women than men, as previously described. ${ }^{18}$ Paradoxically, in our analysis, as observed in other settings, ${ }^{19,20}$ either

Table 6 Study participant characteristics by persistence of statin treatment at follow-up

\begin{tabular}{|c|c|c|c|}
\hline & \multicolumn{2}{|c|}{$\begin{array}{l}\text { Statin treatment } \\
\text { at follow-up, } \\
\text { n (\%)/mean } \pm \text { SD }\end{array}$} & \multirow[t]{2}{*}{$\boldsymbol{P}<$} \\
\hline & $\begin{array}{l}\text { Occasional } \\
\text { II5 (4.2) }\end{array}$ & $\begin{array}{l}\text { Persistent } \\
2,629(95.8)\end{array}$ & \\
\hline Age, years & $67.8 \pm 12.4$ & $61.2 \pm 12.2$ & 0.001 \\
\hline Sex, male & $69(60.0)$ & $1,912(72.7)$ & 0.01 \\
\hline $\begin{array}{l}\text { Hospitalization for } \mathrm{CV} \text { reasons } \\
\text { in the previous year }\end{array}$ & $44(38.3)$ & $973(37.0)$ & NS \\
\hline Presence of diabetes ${ }^{\mathrm{a}, \mathrm{b}}$ & $43(37.4)$ & $650(24.7)$ & 0.001 \\
\hline Presence of CKD ${ }^{a}$ & $17(14.8)$ & $163(6.2)$ & 0.001 \\
\hline $\begin{array}{l}\text { Statin treatment during } \\
\text { hospitalizationc }^{c}\end{array}$ & $65(56.5)$ & $2,167(82.4)$ & 0.001 \\
\hline Prescription of statins at discharge ${ }^{d}$ & $51(52.0)$ & $\mathrm{I}, 988(84.5)$ & 0.001 \\
\hline Total cholesterol,e mg/dL & $185.0 \pm 49.7$ & $193.0 \pm 56.8$ & NS \\
\hline LDL-C, ${ }^{f} \mathrm{mg} / \mathrm{dL}$ & $\mid I 5.4 \pm 40.1$ & $\mid 23.1 \pm 45.9$ & NS \\
\hline LDL-C $>100 \mathrm{mg} / \mathrm{dL}$ & $59(70.2)$ & I,527 (73.7) & NS \\
\hline LDL-C >70 mg/dL & $76(90.5)$ & I,87I (90.3) & NS \\
\hline
\end{tabular}

Notes: ${ }^{a}$ As inferred from hospital discharge database; bas inferred from preadmission prescription of specific drugs; 'as inferred from hospital case history; ${ }^{d}$ as inferred from 2,45 I of 2,744 (89.3\%) hospital case histories; eas inferred from 2,479 of 2,744 (90.3\%) hospital case histories; ' as inferred from 2,I56 of 2,744 (78.6\%) hospital case histories.

Abbreviations: SD, standard deviation; CV, cardiovascular; NS, not significant; CKD, chronic kidney disease; LDL-C, low-density-lipoprotein cholesterol. 
Table 7 Study participant characteristics by level of adherence to statin treatment at follow-up

\begin{tabular}{|c|c|c|c|}
\hline & \multicolumn{2}{|c|}{$\begin{array}{l}\text { Statin treatment at } \\
\text { follow-up, } n(\%) / \text { mean } \pm \text { SD }\end{array}$} & \multirow[t]{2}{*}{$\mathbf{P}<$} \\
\hline & $\begin{array}{l}\text { Nonadherent } \\
\text { MPR < 80\% } \\
\text { I, I } 98(45.6)\end{array}$ & $\begin{array}{l}\text { Adherent } \\
\text { MPR } \geq 80 \% \\
\text { I,43 I (54.4) }\end{array}$ & \\
\hline Age, years & $62.8 \pm 12.4$ & $59.9 \pm 11.8$ & 0.00 \\
\hline Sex, male & $848(70.8)$ & I,064 (74.4) & 0.05 \\
\hline $\begin{array}{l}\text { Hospitalization for CV } \\
\text { reasons in the previous yea }\end{array}$ & $467(39.0)$ & $506(35.4)$ & NS \\
\hline Presence of diabetes ${ }^{\mathrm{a}, \mathrm{b}}$ & $319(26.6)$ & $33 I(23.1)$ & 0.05 \\
\hline Presence of $C K D^{a}$ & $79(6.6)$ & $84(5.9)$ & NS \\
\hline $\begin{array}{l}\text { Statin treatment during } \\
\text { hospitalizationc }^{c}\end{array}$ & $923(77.0)$ & $1,244(86.9)$ & 0.00 \\
\hline $\begin{array}{l}\text { Prescription of statins } \\
\text { at discharge }\end{array}$ & $832(79.1)$ & I, I56 (88.9) & 0.00 \\
\hline Total cholesterol,e $\mathrm{mg} / \mathrm{dL}$ & $155.0 \pm 52.4$ & $191.4 \pm 60.3$ & NS \\
\hline LDL-C, ${ }^{f} \mathrm{mg} / \mathrm{dL}$ & $123.7 \pm 43.8$ & $122.5 \pm 47.6$ & NS \\
\hline LDL-C > $>00$ mg/dL & $224(24.6)$ & $321(27.7)$ & NS \\
\hline LDL-C >70 mg/dL & $84(9.2)$ & $117(10.1)$ & NS \\
\hline
\end{tabular}

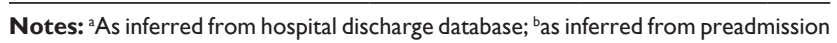
prescription of specific drugs; cas inferred from hospital case history; ${ }^{d}$ as inferred from 2,353 of 2,629 (89.5\%) hospital case histories; eas inferred from 2,37I of 2,629 (90.2\%) hospital case histories; fas inferred from 2,072 of 2,629 (78.8\%) hospital case histories.

Abbreviations: MPR, medication-possession ratio; SD, standard deviation; CV, cardiovascular; NS, not significant; CKD, chronic kidney disease; LDL-C, lowdensity-lipoprotein cholesterol.

during the hospitalization or during the follow-up, the use of statins was lower among elderly patients and patients with diabetes and CKD, who have the highest risk of poor $\mathrm{CV}$ outcomes and who could potentially benefit the most from sustained therapy. These findings suggest the need to design educational programs targeted at patients at high risk of underuse of medications in secondary CV prevention.

Table 8 Daily dose of different types of statins prescribed during follow-up to those persistent with adherence to treatment $\geq 80 \%$

\begin{tabular}{llll}
\hline $\begin{array}{lll}\text { Statin prescribed } \\
\text { during follow-up }\end{array}$ & Daily dose, & \multicolumn{2}{l}{ Patients treated } \\
\cline { 3 - 4 } & $\mathbf{m g}$ & $\mathbf{n}$ & $\%$ \\
\hline Atorvastatin & $\leq 20$ & 280 & 44.2 \\
& $>20-\leq 40$ & 302 & 47.7 \\
& $>40$ & 51 & 8.1 \\
Pravastatin & $\leq 30$ & 34 & 26.4 \\
& $>30-\leq 60$ & 92 & 71.3 \\
Rosuvastatin & $>60$ & 3 & 2.3 \\
& $\leq 10$ & 29 & 53.7 \\
Simvastatin & $>10-\leq 20$ & 23 & 42.6 \\
& $>20$ & 2 & 3.7 \\
& $\leq 30$ & 275 & 45.7 \\
& $>30-\leq 60$ & 321 & 53.3 \\
& $>60$ & 6 & 1.0 \\
\hline
\end{tabular}

Note: Fourteen patients treated with other statins were not considered.
Table 9 Logistic regression analysis to predict 2-year nonadherence to statin treatment

\begin{tabular}{lllll}
\hline & RR & $\mathbf{9 5 \%} \mathbf{C l}$ & P-value \\
\cline { 3 - 4 } & & Inferior & Superior & \\
\hline Age, years & 1.019 & $1.01 \mathrm{I}$ & 1.026 & 0.000 \\
Sex & 0.949 & 0.787 & 1.143 & 0.580 \\
Previous statin treatment & 0.664 & 0.542 & 0.814 & 0.000 \\
Presence of diabetes & 1.296 & 1.046 & 1.605 & 0.018 \\
Previous CV hospitalizations & 1.301 & 1.076 & 1.573 & 0.007 \\
Presence of CKD & 0.907 & 0.647 & 1.270 & 0.569 \\
Statin treatment during & 0.564 & 0.454 & 0.701 & 0.000 \\
hospitalization & & & & \\
Antihypertensive/antiplatelet & 0.380 & 0.243 & 0.593 & 0.000 \\
treatment & & & & \\
Statin & & & & \\
Atorvastatin (reference) & & & & \\
$\quad$ Pravastatin & 1.642 & 1.253 & $2.15 \mathrm{I}$ & 0.000 \\
$\quad$ Rosuvastatin & 1.576 & 1.055 & 2.355 & 0.026 \\
$\quad$ Simvastatin & 1.229 & 1.031 & 1.466 & 0.022 \\
$\quad$ Other statins & 2.429 & 1.233 & 4.785 & 0.010 \\
\hline
\end{tabular}

Abbreviations: $\mathrm{Cl}$, confidence interval; $\mathrm{RR}$, relative risk; $\mathrm{CV}$, cardiovascular; CKD, chronic kidney disease.

Unfortunately, preliminary reports suggest that the adoption of quality-improvement programs have modest effects on improving adherence to the use of life-saving therapies. ${ }^{21,22}$ We found that total and LDL cholesterol levels were significantly lower in statin-untreated patients either during the hospitalization or during the follow-up, even if nearly $90 \%$ of our patients had a value of LDL cholesterol $>70 \mathrm{mg} / \mathrm{dL}$. These findings are in contrast with current therapeutic guidelines $^{6,8}$ that tends to emphasizes the need to reach a particular LDL cholesterol target, ie, $<100 \mathrm{mg} / \mathrm{dL}$ or $<70 \mathrm{mg} / \mathrm{dL}$ in very high-risk patients. Conversely, in the present study, lipid levels were not associated with adherence to treatment in follow-up. In addition, the absence of any relationship between lipid levels and the choice of statin to prescribe provides evidence that physicians treat statins as a class and do not choose their statins based on clinical trial evidence, as previously observed. ${ }^{23}$ Importantly, we also observed that among the strongest factors associated with consistent use of statins, there was baseline use of other evidence-based medications in the form of antihypertensive and antiplatelet drugs. From previous studies, it is clear that an important factor in long-term use of statins is prescription at the time of discharge after an acute event. ${ }^{24,25}$ In a single-center study of 600 patients, ${ }^{13} 23 \%$ of patients with CAD documented by coronary angiography and prescribed a statin at discharge were not using a statin at an average of 3 years of follow-up. Our results were similar: during the 2-year follow-up, the majority of occasional patients or nonadherent patients had not received a statin prescription at hospital discharge. 
In our study, $606(16.9 \%)$ patients were on statins before the hospital admission for MI. This is in accordance with findings of other studies, ${ }^{26,27}$ where only $15 \%-30 \%$ of patients admitted for MI were taking statins before their event, but with $37.9 \%$ of patients with a previous hospitalization for $\mathrm{CV}$ reasons, this emphasizes the lack of efficacious primary and secondary prevention of CV disease.

Our study has a number of strengths. First, it included all patients with an MI admitted to hospitals located in nine Italian regions, and unlike clinical trials, involved a representative sample of unselected subjects (both men and women) and reflected a real-world setting. Second, we had information not only on statin treatment posthospitalization but also information regarding the period before and during hospitalization containing variables not typically available in prescription claim databases. Therefore, we were able to describe in each patient the links between different setting and clinical condition.

Our study has several limitations. First, information on the severity of MI was not available to us. Second, we restricted our analysis to recent years (2003-2007) to reflect the therapeutic policy after the publication of the stringent guidelines for lipid lowering in patients with CAD. ${ }^{6,7}$ Third, the reasons for discontinuation of statins are not available in the claim databases. Also, we used issued prescriptions (information derived from electronic records) to estimate actual pill intake. However, this is a standard method used in population-based databases. ${ }^{28}$ Fourth, as is true of most observational studies, we may not have been able to completely control for potential confounders related to severity of illness or excess comorbidities. Therefore, although we adjusted for a number of important risk factors and potential confounders, our study may have been affected by residual confounding. Finally, a further weakness is our lack of follow-up on total and LDL cholesterol measurement. We believe that it may be considered unimportant. In the 1,431 patients with a MPR $\geq 80 \%$, we determined the dose of statin according to defined daily dose. A standard statin regimen (ie, 20-40 mg simvastatin daily) is expected to reduce LDL cholesterol by about a third, while more potent statins (ie, 40-80 mg atorvastatin daily or $10-20 \mathrm{mg}$ rosuvastatin daily) can halve LDL cholesterol. ${ }^{29}$ We believe that adherence to treatment and determination of daily dose could be considered good indicators of efficacy in population-based studies.

\section{Conclusion}

Patients after an $\mathrm{MI}$ are at high risk of CV events (including death), and should be treated aggressively in the absence of clear contraindications. Since the statin-undertreatment rate in routine care is still high, physicians need to increase the awareness of patients regarding the implications of underuse of their medications (sometimes despite doctors' recommendations). It is important to emphasize that discontinuation of statin therapy following an acute MI is associated with higher total mortality, ${ }^{30}$ so physicians have to encourage higher adherence to effective cardioprotective therapy. Although continued improvement in short-term use and prescription of these agents is needed, considerable attention must also be focused on understanding and improving long-term adherence to achieve the full potential of these treatments to improve clinical outcomes.

\section{Disclosure}

This work was supported by an unconditional grant of Pfizer Italy. The authors report no other conflicts of interest in this work.

\section{References}

1. [No authors listed]. Randomised trial of cholesterol lowering in 4444 patients with coronary heart disease: the Scandinavian Simvastatin Survival Study (4S). Lancet. 1994;344:1383-1389.

2. LIPID Study Group (Long-term Intervention with Pravastatin in Ischaemic Disease). Long-term effectiveness and safety of pravastatin in 9014 patients with coronary heart disease and average cholesterol concentrations: the LIPID trial follow-up. Lancet. 2002;359:1379-1387.

3. Heart Protection Study Collaborative Group. MRC/BHF Heart Protection Study of cholesterol lowering with simvastatin in 20,536 high-risk individuals; a randomised placebo-controlled trial. Lancet. 2002;360:7-22.

4. LaRosa JC, Grundy SM, Waters DD, et al. Intensive lipid lowering with atorvastatin in patients with stable coronary disease. $N$ Engl $J$ Med. 2005;352:1425-1435.

5. Schwartz GG, Olsson AG, Ezekowitz MD, et al. Effects of atorvastatin on early recurrent ischemic events in acute coronary syndromes: the MIRACL study: a randomized controlled trial. JAMA. 2001;285:1711-1718.

6. Expert Panel on Detection, Evaluation, and Treatment of High Blood Cholesterol in Adults. Executive summary of the third report of the National Cholesterol Education Program (NCEP) Expert Panel on Detection, Evaluation, and Treatment of High Blood Cholesterol in Adults (Adult Treatment Panel III). JAMA. 2001;285: 2486-2497.

7. De Backer G, Ambrosioni E, Borch-Johnsen K, et al. European guidelines on cardiovascular disease prevention in clinical practice. Third Joint Task Force of European and Other Societies on Cardiovascular Disease Prevention in Clinical Practice. Eur Heart J. 2003;24: $1601-1610$.

8. Smith SC, Allen J, Blair S, et al. AHA/ACC guidelines for secondary prevention for patients with coronary and other atherosclerotic vascular disease: 2006 update: endorsed by the National Heart, Lung, and Blood Institute. Circulation. 2006;113:2363-2372.

9. National Committee for Quality Assurance. The State of Managed Care Quality. Washington: NCQA; 1999.

10. Ho PM, Magid DJ, Shetterly SM, et al. Medication nonadherence is associated with a broad range of adverse outcomes in patients with coronary artery disease. Am Heart J. 2008;155:722-729.

11. Shah ND, Dunlay SM, Ting HH, et al. Long-term medication adherence after myocardial infarction: experience of a community. Am J Med. 2009;122:e7-e13. 
12. Eagle KA, Montoye CK, Riba AL, et al. Guideline-based standardized care is associated with substantially lower mortality in Medicare patients with acute myocardial infarction: the American College of Cardiology's Guidelines Applied in Practice (GAP) Projects in Michigan. J Am Coll Cardiol. 2005;46:1242-1248.

13. Muhlestein JB, Horne BD, Bair TL, et al. Usefulness of in-hospital prescription of statin agents after angiographic diagnosis of coronary artery disease in improving continued compliance and reduced mortality. Am J Cardiol. 2001;87:257-261.

14. Di Bari M, Balzi D, Roberts AT, et al. Prognostic stratification of folder persons based on simple administrative data: development and validation of the "Silver Code," to be used in emergency department triage. J Gerontol A Biol Sci Med Sci. 2010;65:159-164.

15. Ministero del Lavoro, della Salute e delle Politiche Sociali. Rapporto annuale sulle attivita' di ricovero ospedaliero. 2005. Available from: http://www.salute.gov.it/. Accessed April 24, 2009.

16. WHO Collaborating Centre for Drug Statistics Methodology [website on the Internet]. Available from: http://www.whocc.no. Accessed October 14, 2014.

17. Catalan VS, LeLorier J. Predictors of long-term persistence on statins in a subsidized clinical population. Value Health. 2000;3:417-426.

18. Wei L, Wang J, Thompson P, Wong S, Struthers AD, MacDonald TM. Adherence to statin treatment and readmission of patients after myocardial infarction: a six year follow up study. Heart. 2002;88:229-233.

19. Califf RM, DeLong E, Ostbyte T, et al. Underuse of aspirin in a referral population with documented coronary artery disease. Am J Cardiol. 2002;89:653-661.

20. Newby LK, LaPointe NM, Chen AY, et al. Long-term adherence to evidence-based secondary prevention therapies in coronary artery disease. Circulation. 2006;113:203-212.

21. Mehta RH, Montoye CK, Gallogly M, et al. Improving quality of care for acute myocardial infarction: the Guidelines Applied in Practice (GAP) Initiative. JAMA. 2002;287:1269-1276.
22. LaBresh KA, Ellrodt AG, Gliklich R, Liljestrand J, Peto R. Get with the guidelines for cardiovascular secondary prevention: pilot results. Arch Intern Med. 2004;164:203-209.

23. Brophy JM, Costa V. Statin wars following coronary revascularization evidence-based clinical practice? Can J Cardiol. 2006;22:54-58.

24. Fonarow GC, Gawlinski A, Moughrabi S, Tillisch JH. Improved treatment of coronary heart disease by implementation of a Cardiac Hospitalization Atherosclerosis Management Program (CHAMP). Am J Cardiol. 2001;87:819-822.

25. Simpson E, Beck C, Richard H, Eisenberg MJ, Pilote L. Drug prescriptions after acute myocardial infarction: dosage, compliance, and persistence. Am Heart J. 2003;145:438-444.

26. Spencer FA, Fonarow GC, Frederick PD, et al. Early withdrawal of statin therapy in patients with non-ST-segment elevation myocardial infarction: National Registry of Myocardial Infarction. Arch Intern Med. 2004;164:2162-2168.

27. Jackevicius CA, Mamdani M, Tu JV. Adherence with statin therapy in elderly patients with and without acute coronary syndromes. JAMA. 2002;288:462-467.

28. Jick SS, Kaye JA, Vasilakis-Scaramozza C, et al. Validity of the general practice research database. Pharmacotherapy. 2003;23:686-689.

29. Cholesterol Treatment Trialists (CTT) Collaboration, Baigent C, Blackwell L, et al. Efficacy and safety of more intensive lowering of LDL cholesterol: a meta-analysis of data from 170,000 participants in 26 randomised trials. Lancet. 2010;376:1670-1681.

30. Daskalopoulou SS, Delaney JA, Filion KB, Brophy JM, Mayo NE, Suissa S. Discontinuation of statin therapy following an acute myocardial infarction: a population-based study. Eur Heart J. 2008;29: 2083-2091.
ClinicoEconomics and Outcomes Research

\section{Publish your work in this journal}

ClinicoEconomics \& Outcomes Research is an international, peerreviewed open-access journal focusing on Health Technology Assessment, Pharmacoeconomics and Outcomes Research in the areas of diagnosis, medical devices, and clinical, surgical and pharmacological intervention. The economic impact of health policy and health systems

\section{Dovepress}

organization also constitute important areas of coverage. The manuscript management system is completely online and includes a very quick and fair peer-review system, which is all easy to use. Visit http://www.dovepress.com/testimonials.php to read real quotes from published authors. 